\title{
Sonderausgaben aus den Sitzungsberichten
}

Verlag der Akademie der Wissenschaften

In Kommission bei Walter de Gruyter u. Co.

Bisher sind erschienen:

Kolbe, W., Bericht über eine Reise in Messenien. $S B$. $1905 \ldots \ldots \ldots \ldots \mathscr{R} \mathscr{M}$ I.-

- Das Kalliasdekret. $S B$. $1927 \ldots \ldots \ldots \ldots \ldots \ldots \ldots \ldots \ldots \ldots \ldots$ " I.-

- Studien über das Kalliasdekret. Bausteine zu einer Geschichte des Schatzes

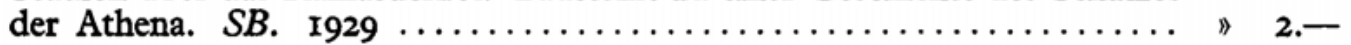

- Die Kleon-Schatzung des Jahres 425/4. $S B$. 1930............... " 2.

- Kalliasdekrete und "Sinking-Fund". $S B$. 1933 ...............

- Thukydides und die Urkunde IG I2 63. $S B$. I937 ........... " I.- 